\title{
Amide proton transfer-weighted magnetic resonance imaging of human brain aging at 3 Tesla
}

\author{
Zewen Zhang ${ }^{1,2}$, Caiqing Zhang ${ }^{3}$, Jian Yao ${ }^{1}$, Fei Gao ${ }^{1}$, Tao Gong ${ }^{1}$, Shanshan Jiang ${ }^{2}$, Weibo Chen ${ }^{4}$, \\ Jinyuan Zhou ${ }^{2}$, Guangbin Wang ${ }^{1}$ \\ ${ }^{1}$ Department of MR, Shandong Medical Imaging Research Institute, Shandong University, Jinan 250021, China; ${ }^{2}$ Division of MR Research, \\ Department of Radiology, Johns Hopkins University, Maryland, USA; ${ }^{3}$ Department of Respiratory Medicine, Shandong Provincial Qianfoshan \\ Hospital, Shandong University, Jinan 250014, China; ${ }^{4}$ Philips Healthcare, Shanghai 200072, China
}

Correspondence to: Guangbin Wang, MD, PhD. Department of MR, Shandong Medical Imaging Research Institute, Shandong University, Jinan 250021, China. Email: cjr.wangguangbin@vip.163.com.

Background: Amide proton transfer-weighted (APTw) imaging has been revealed to hold great potential in the diagnosis of several brain diseases. The purpose of this proof-of-concept study was to evaluate the feasibility and value of APTw magnetic resonance imaging (MRI) in characterizing normal brain aging.

Methods: A total of 106 healthy subjects were recruited and scanned at 3.0 Tesla, with APTw and conventional magnetization transfer (MT) sequences. Quantitative image analyses were performed in 12 regions of interest (ROIs) for each subject. The APTw or MT ratio (MTR) signal differences among five age groups (young, mature, middle-aged, young-old, and middle-old) were assessed using the one-way analysis of variance, with the Benjamini-Hochberg correction for multiple comparisons. The relationship between APTw and MTR signals and the age dependencies of APTw and MTR signals were assessed using the Pearson correlation and non-linear regression.

Results: There were no significant differences between the APTw or MTR values for males and females in any of the 12 ROIs analyzed. Among the five age groups, there were significant differences in the three white matter regions in the temporal, occipital, and frontal lobes. Overall, the mean APTw values in the older group were higher than those in the younger group. Positive correlations were observed in relation to age in most brain regions, including four with significant positive correlations ( $r=0.2065-0.4182)$ and five with increasing trends. As a comparison, the mean MTR values did not appear to be significantly different among the five age groups. In addition, the mean APTw and MTR values revealed significant positive correlations in 10 ROIs ( $r=0.2214-0.7269)$ and a significant negative correlation in one ROI (entorhinal cortex, $r=-0.2141$ ).

Conclusions: Our early results show that the APTw signal can be used as a promising and complementary imaging biomarker with which normal brain aging can be evaluated at the molecular level.

Keywords: Aging; chemical exchange saturation transfer (CEST); amide proton transfer imaging; molecular imaging; biomarkers

Submitted Nov 20, 2019. Accepted for publication Feb 18, 2020.

doi: 10.21037 /qims.2020.02.22

View this article at: http://dx.doi.org/10.21037/qims.2020.02.22

\section{Introduction}

As the brain ages, a series of biochemical, molecular, functional, and structural changes occur (1). A large number of previous studies have been conducted exploring healthy and pathological aging processes and have revealed domains of functioning that are most susceptible to, for example, cerebral arterial stiffening (2-4), inflammation (5-7), oxidative stress (8), and poor glucoregulation (9). Magnetic 
resonance imaging (MRI) has been used widely to explore age-related neural changes $(10,11)$. Structural MRI studies, for example, have demonstrated consistent age-related changes $(12,13)$, and functional MRI (fMRI) has discovered alterations in functional connectivity with age (13). Positron emission tomography (PET) research has involved the neurochemical aspects of aging in healthy humans, such as glucose metabolism (14), tau deposition $(15,16)$, and $\beta$-amyloid deposition (17).

As a specific type of chemical exchange saturation transfer (CEST) imaging $(18,19)$, amide proton transfer-weighted (APTw) MRI is able to detect cellular endogenous mobile peptides and proteins in a non-invasive manner (20). This promising molecular imaging technique has been applied to several brain diseases since it was first reported in 2003 (21), ranging from cerebral/other tumors (22-25) to other nononcologic neurological conditions, such as strokes (26-28), Parkinson's disease (29), and traumatic brain injury (30,31). Remarkably, a recent study demonstrated that the APTw signal intensities in multiple brain regions were significantly higher in mild cognitive impairment patients than in normal controls (32). Nonetheless, whether APTw MRI can be an effective tool for researching normal brain aging is still uncharted territory. This proof-of-concept research attempted to apply APTw MRI to healthy people in a broad age range to explore characteristic changes during the aging of the normal brain. Conventional magnetization transfer (MT) imaging was used as a comparison, which was quantified by the MT ratio (MTR) associated with semisolid macromolecules in tissue (33).

\section{Methods}

\section{Subjects}

This study was approved by the local institutional review board. All subjects gave written informed consent before participating in this study. Inclusion criteria for the study were as follows: aged between 25 and 75 years old; normal results of neurological examinations confirmed by an expert neurologist; no history of head trauma, central nervous system infection, or cerebral structural lesions; and no psychiatric diseases or exposure to psychotropic drugs.

\section{MRI protocol}

One 3 Tesla MRI scanner (Achieva; Philips Medical
Systems, Best, The Netherlands) was used in this study. A multi-offset, single-slice, single-shot turbo spin echo (TSE) with combined APTw and conventional MT imaging, acquisition protocol was applied to the maximum crosssectional areas of the hippocampus, the pons, the entorhinal cortex, and the thalamus (four slices). The sequence parameters used were: radiofrequency $(\mathrm{RF})$ saturation power $=2 \mu \mathrm{T}$; saturation duration $=800 \mathrm{~ms}$; repetition time $=3,000 \mathrm{~ms}$; echo time $=11 \mathrm{~ms}$; TSE factor $=54$; matrix $=105 \times 100$ (reconstructed to be $256 \times 256$ ); field of view $=230 \times 220 \mathrm{~mm}^{2}$; and slice thickness $=6 \mathrm{~mm}$. The 32 offsets were: $0, \pm 0.25, \pm 0.5, \pm 0.75, \pm 1, \pm 1.5, \pm 2[2], \pm 2.5[2], \pm 3$ [2], \pm 3.25 [2], \pm 3.5 [6], \pm 3.75 [2], $\pm 4[2], \pm 4.5, \pm 5, \pm 6$, and $+15.6 \mathrm{ppm}$ (the numbers in square brackets display the number of acquisitions, which was 1 if not specified). More offsets were applied near $0 \mathrm{ppm}$ to improve the fitting accuracy of $\mathrm{B}_{0}$ maps, and more offsets were used around $\pm 3.5 \mathrm{ppm}$ to increase the interpolation accuracy of APTw data for $\mathrm{B}_{0}$ correction (34). This combined APTw/MT scan required about 12 minutes for each subject ( $3 \mathrm{~min}$ per slice).

\section{Data analysis}

The Interactive Data Language (IDL, version 8; Exelis Visual Information Solutions, Inc.) was used to analyze image data. The acquired MT/APT image series for each slice was registered to the saturated image at $3.5 \mathrm{ppm}$ to reduce possible motion artifacts during the scanning, using a rigid-body transformation of three degrees of freedom, as described previously (35). The measured MT spectra $\left(M_{\mathrm{sat}} /\right.$ $\mathrm{M}_{0}$, plotted as a function of saturation frequency offset, relative to water, 31 offsets, in which $M_{\text {sat }}$ and $M_{0}$ are the signal intensities with and without selective RF irradiation, respectively) were corrected for the $B_{0}$ field inhomogeneity effect on a voxel-by-voxel basis (29). Briefly, these MT spectra were fitted through all offsets using the 12 thorder polynomial on a voxel-by-voxel basis (36). The fitted curves were interpolated using an offset resolution of $1 \mathrm{~Hz}$. Following this, the corresponding $\mathrm{B}_{0}$ field inhomogeneity was calculated according to the deviation of the minimum of the fitted curve from $0 \mathrm{ppm}$. Finally, the original MT spectra were interpolated and centered along the direction of the offset axis to shift their lowest intensities to $0 \mathrm{ppm}$. The realigned MT spectra were interpolated back to 31 offsets. For the conventional semi-solid MT imaging, we defined: MTR $=1-M_{\text {sat }}(+15.6 \mathrm{ppm}) / \mathrm{M}_{0}$. The APTw images were 
Table 1 Gender and age distribution of normal subjects recruited in this study

\begin{tabular}{lccc}
\hline Group & Number of subjects (male/female) & Age range (years) & Mean age (years) \\
\hline Young (Y) & $21(10 / 11)$ & $25-34$ & $30.1 \pm 2.8$ \\
Mature (M) & $23(13 / 10)$ & $35-44$ & $39.8 \pm 3.0$ \\
Middle-aged (MA) & $23(8 / 15)$ & $45-54$ & $49.5 \pm 2.9$ \\
Young-old (YO) & $22(9 / 13)$ & $55-64$ & $60.1 \pm 2.7$ \\
Middle-old (MO) & $17(9 / 8)$ & $65-75$ & $69.8 \pm 3.2$ \\
Total & $106(49 / 57)$ & $25-75$ & $49.0 \pm 13.9$ \\
\hline
\end{tabular}

Data are means \pm standard deviations.

created by the MTR asymmetry $\left(\mathrm{MTR}_{\text {asym }}\right)$ at the offsets of $\pm 3.5 \mathrm{ppm}(21): \mathrm{MTR}_{\text {asym }}(3.5 \mathrm{ppm})=\mathrm{M}_{\text {sat }}(-3.5 \mathrm{ppm}) /$ $\mathrm{M}_{0}-\mathrm{M}_{\mathrm{sat}}(+3.5 \mathrm{ppm}) / \mathrm{M}_{0}$.

Based on the structural $M_{\text {sat }}(3.5 \mathrm{ppm})$ and $M_{0}$ images that were co-registered with APTw for each subject, two radiologists (Zewen Zhang and Jian Yao, who have had 5 and 28 years of experience in neurological imaging, respectively) reviewed all MR images and manually drew 12 regions of interest (ROIs), in consensus. These 12 ROIs (Figure S1) were as follows: the hippocampus, the white matter in the temporal lobe, and the gray matter in the temporal lobe (the first slice); the pons, the white matter in the occipital lobe, and the gray matter in the occipital lobe (the second slice); the entorhinal cortex, the white matter in the frontal lobe, and the gray matter in the frontal lobe (the third slice); and the thalamus, the putamen, and the caudate nucleus (the fourth slice). For each subject, the mean APTw and MTR values were obtained for each ROI, and data from the left and right hemispheres were combined for further analysis.

\section{Statistical analysis}

All data in this study were analyzed with SPSS 25.0 (International Business Machines Corporation) statistical software. $\mathrm{P}<0.05$ was considered statistically significant. After testing for normality, the independent samples $t$-test was used to analyze the statistical differences between the mean APTw or MTR values for male and female subjects. A one-way analysis of variance (ANOVA) was applied to assess the statistical differences among the mean APTw or MTR values for five different age groups (37-39). The Benjamini-Hochberg correction, as a practical and powerful approach (40), was used as a post-hoc test, with a false discovery rate of 0.05 . Pearson correlation analyses were performed to assess the correlations between APTw, MTR, and age, with additional nonlinear regression analyses adopted for the APTw and MTR signals and age.

\section{Results}

\section{Patient demographics}

From November 2017 to December 2018, 106 healthy subjects (49 males and 57 females; age range, 25-75 years) who met the inclusion criteria were enrolled for this study and participated in MRI scanning. All subjects were divided into five age groups at ten-year intervals (37-39): young (25-34 years; $\mathrm{n}=21$ ); mature ( $35-44$ years; $\mathrm{n}=23$ ); middleaged ( $45-54$ years; $n=23)$; young-old $(55-64$ years; $n=22)$; and middle-old $(65-75$ years; $\mathrm{n}=17)$. The descriptive information for these five age groups is provided in Table 1.

\section{Comparison of APTw and MTR images for different ages}

Two typical examples of MTR and APTw images from the mature and middle-old groups are shown in Figure 1. Compared to the mature subject (female; $37 \mathrm{y}$ ), the middleold subject (male; 66 y) demonstrated clearly visible, relatively higher MTR and APTw signals in most brain regions.

Quantitatively, there were no significant differences between the APTw or MTR values for the male and female groups in all ROIs. Differences in ROI-based mean APTw and MTR values among the five age groups are displayed in Figures 2 and 3, respectively. Among the five age groups, the APTw values were significantly different in 3 of 12 ROIs. 

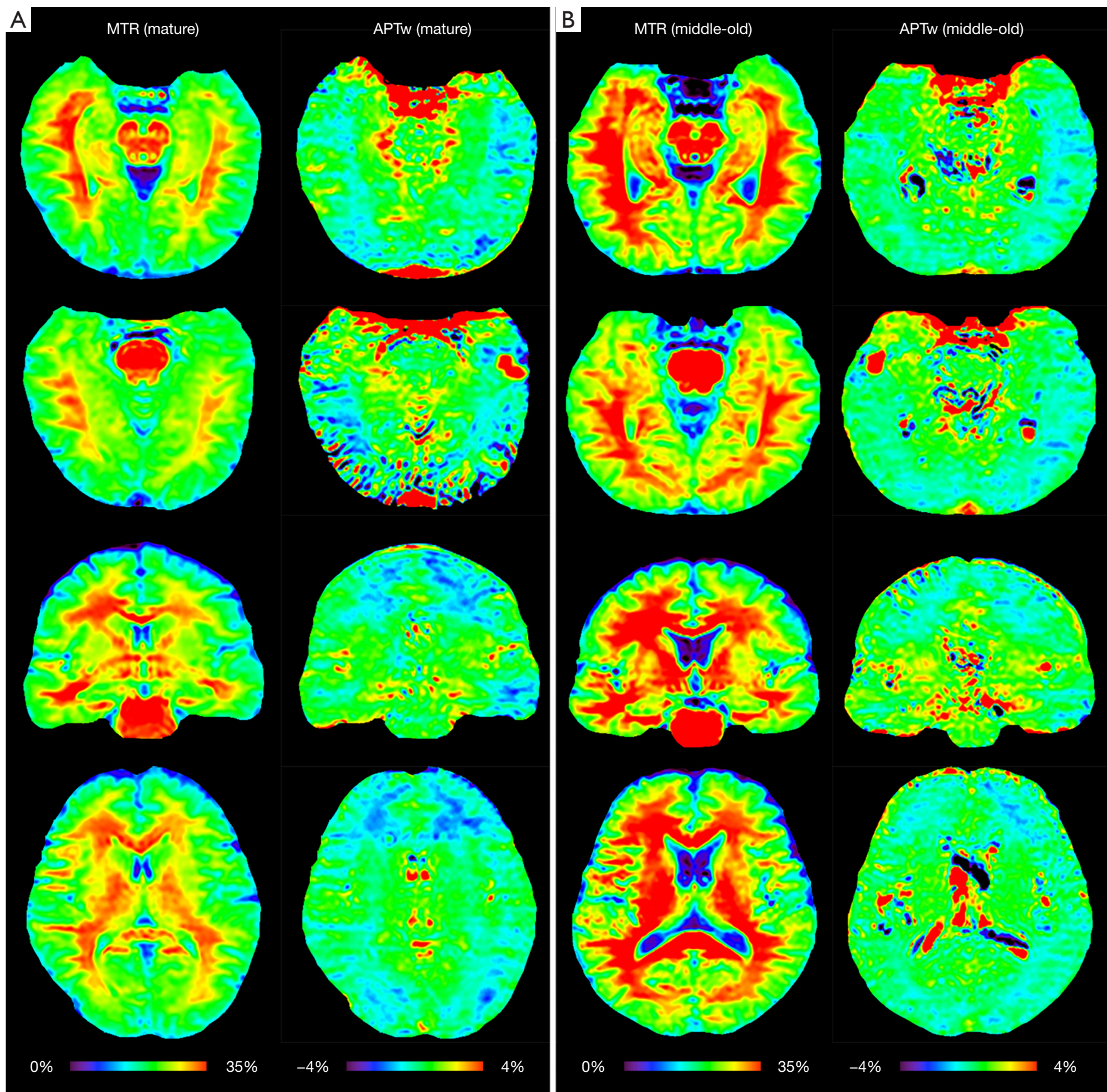

Figure 1 MTR and APTw images for two examples from the mature (female; $37 \mathrm{y}$; A) and middle-old (male; 66 y; B) groups. MTR, magnetization transfer ratio; APTw, Amide proton transfer-weighted.

Notably, significant APTw changes were observed in three white matter ROIs. In the white matter in the temporal lobe, the APTw values of the young, mature, middle-aged, and young-old groups were significantly lower $(\mathrm{P}=0.0063$,
$0.0051,0.0063$, and 0.0234 , respectively) than that of the middle-old group. In the white matter in the occipital lobe, the APTw values of the mature, middle-aged, and young-old groups were significantly lower $(\mathrm{P}=0.0027$, 

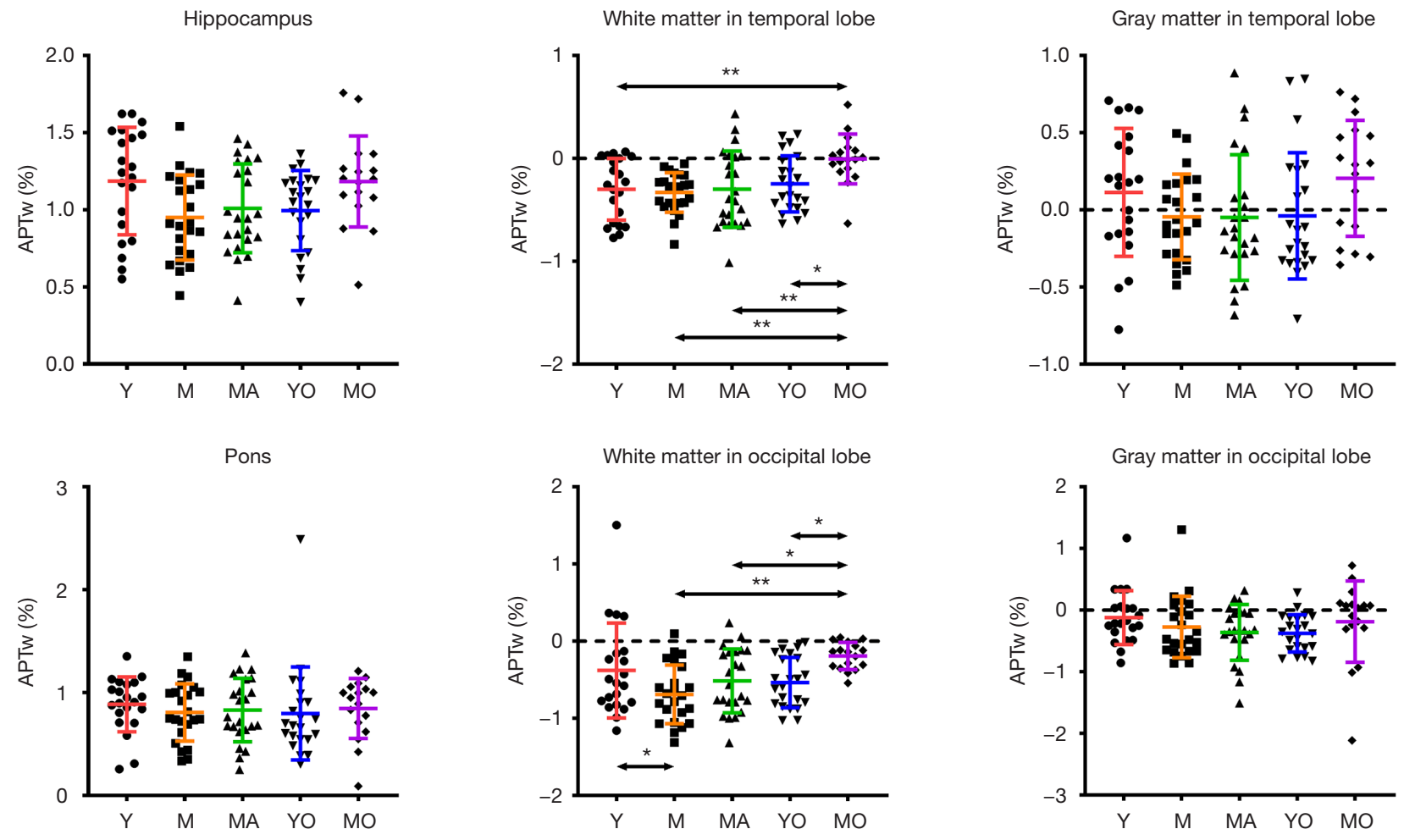

Entorhinal cortex

White matter in frontal lobe
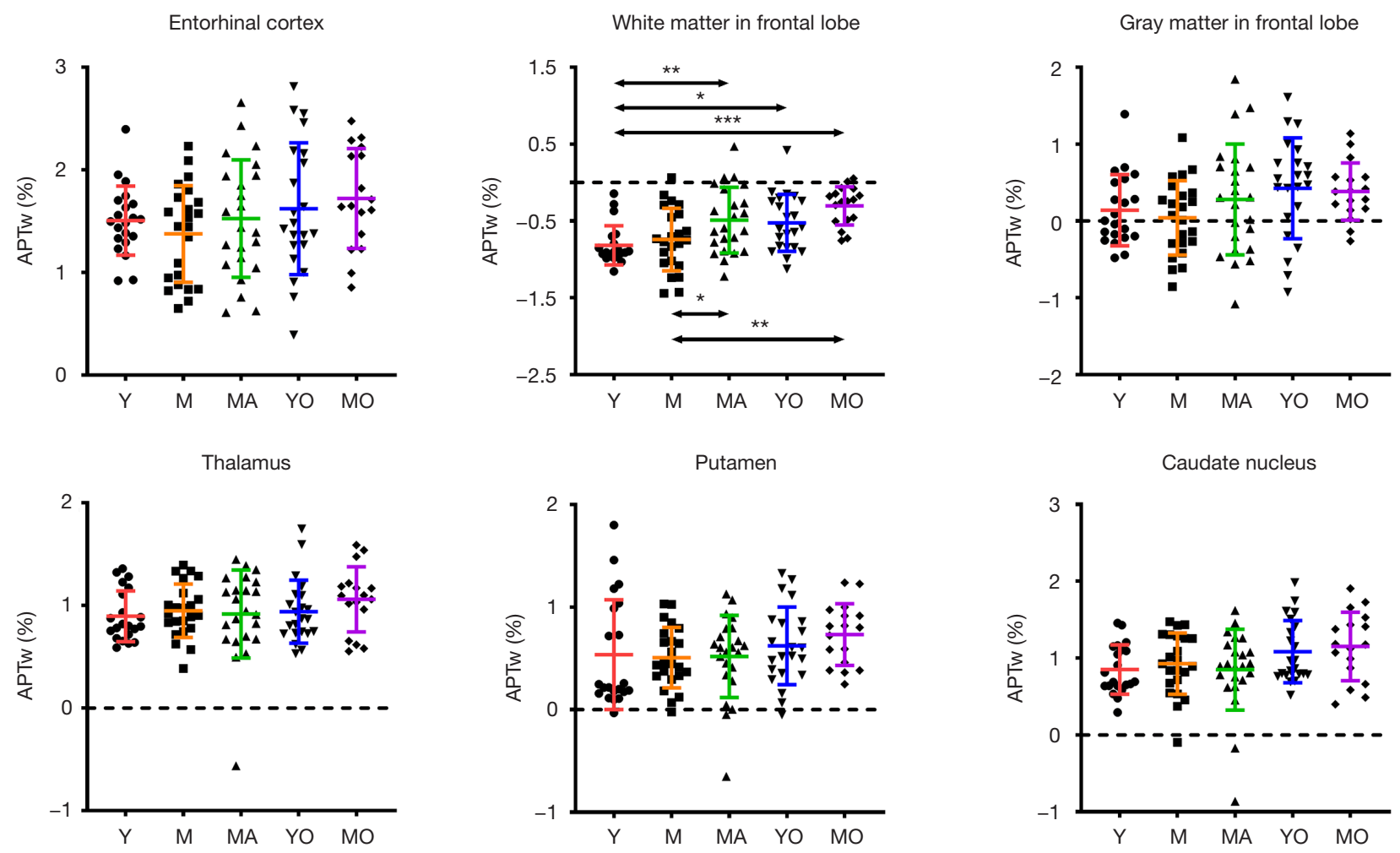

Figure 2 APTw values among the five different age groups were analyzed using the one-way analysis of variance (ANOVA), with the Benjamini-Hochberg correction for multiple testing. *, $\mathrm{P}<0.05$, **, $\mathrm{P}<0.01$, ${ }^{* * *}, \mathrm{P}<0.001$. Y, young; M, mature; MA, middle-aged; YO, young-old; MO, middle-old. APTw, Amide proton transfer-weighted. 

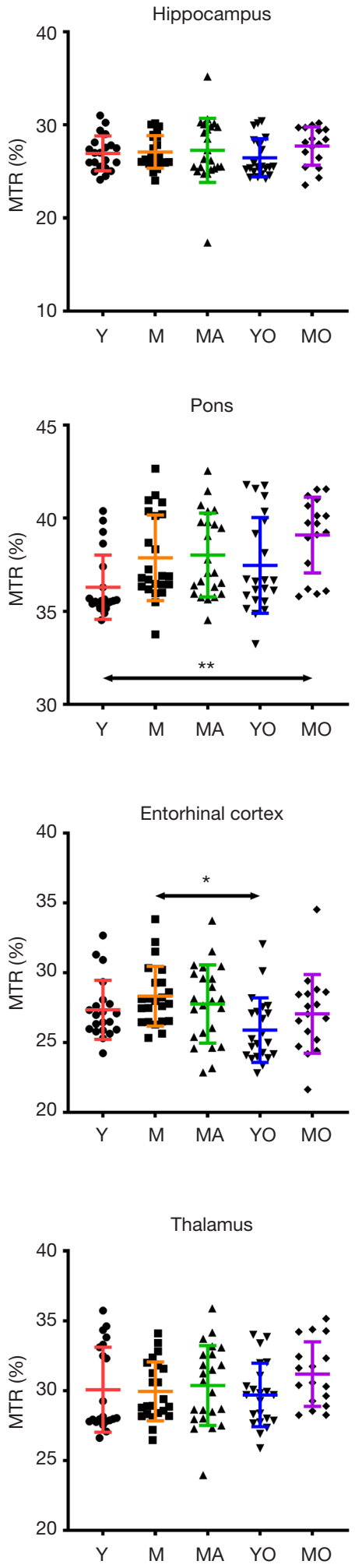
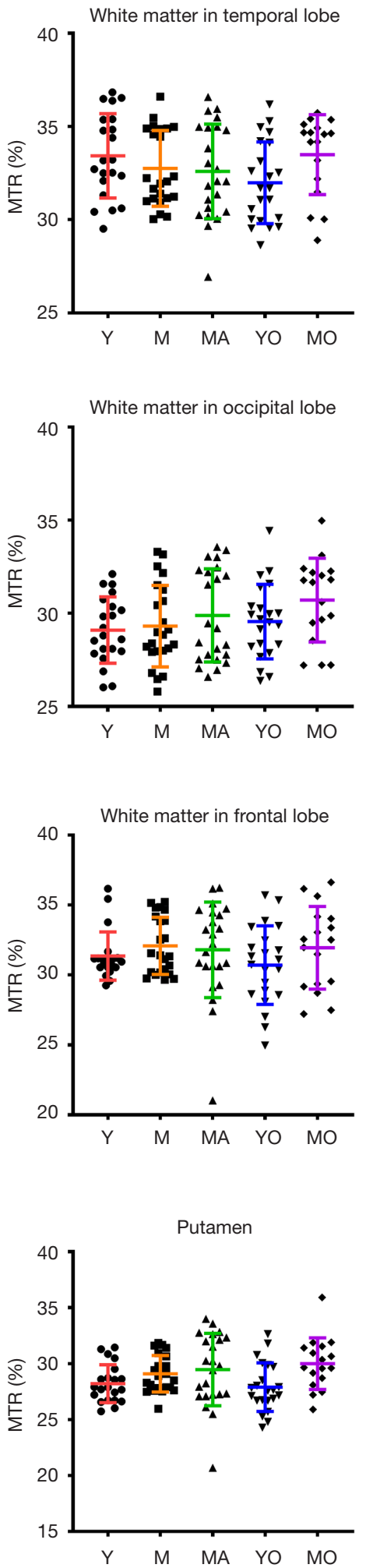
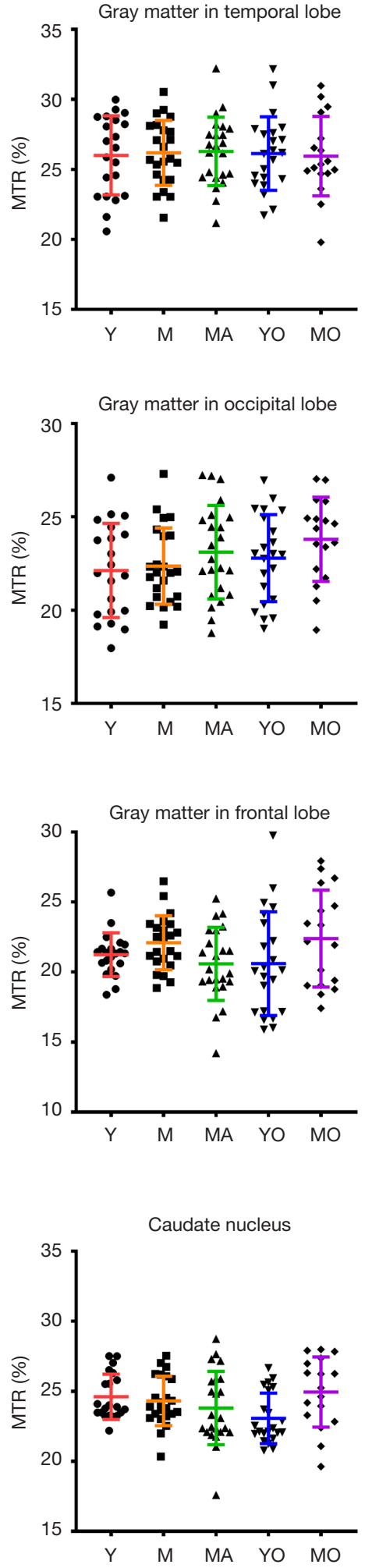

Figure 3 MTR values among the five different age groups were analyzed using the one-way analysis of variance (ANOVA), with the Benjamini-Hochberg correction for multiple testing. * $, \mathrm{P}<0.05,{ }^{* *}, \mathrm{P}<0.01$. Y, young; M, mature; MA, middle-aged; YO, young-old; MO, middle-old. MTR, magnetization transfer ratio. 
0.0403 , and 0.0403 , respectively) than that of the middleold group. Note that the APTw value of the young group was significantly higher $(\mathrm{P}=0.0403)$ than that of the mature group. In the white matter in the frontal lobe, the APTw values of the young group were significantly lower than those of the middle-aged, young-old, and middle-old groups ( $\mathrm{P}=0.0099,0.0211$, and 0.0003 , respectively), and the APTw values of the mature group were also significantly lower than those of the middle-aged and middle-old groups ( $\mathrm{P}=0.0366$ and 0.0011 , respectively). As a comparison, the MTR values had significant differences in 2 of 12 ROIs. Namely, the MTR values in the pons were significantly lower $(\mathrm{P}=0.0018)$ in the young group than in the middleold group, whereas the MTR values in the entorhinal cortex were significantly higher $(\mathrm{P}=0.0119)$ in the mature group than in the young-old group.

\section{Correlation analyses}

As shown in Figure 4 and Table 2, there were significant positive correlations between the APTw and MTR values in 10 of 12 ROIs analyzed: the hippocampus ( $r=0.4016$, $\mathrm{P}<0.0001)$; the white matter in the temporal lobe $(\mathrm{r}=0.7269$, $\mathrm{P}<0.0001)$; the pons $(\mathrm{r}=0.4062, \mathrm{P}<0.0001)$; the white matter in the occipital lobe $(\mathrm{r}=0.6496, \mathrm{P}<0.0001)$; the gray matter in the occipital lobe $(\mathrm{r}=0.4690, \mathrm{P}<0.0001)$; the white matter in the frontal lobe $(\mathrm{r}=0.4638, \mathrm{P}<0.0001)$; the gray matter in the frontal lobe $(\mathrm{r}=0.2214, \mathrm{P}=0.0226)$; the thalamus $(\mathrm{r}=0.5907, \mathrm{P}<0.0001)$; the putamen $(\mathrm{r}=0.4110, \mathrm{P}<0.0001)$; and the caudate nucleus $(\mathrm{r}=0.4821, \mathrm{P}<0.0001)$. However, the APTw values indicated a significant negative correlation with the MTR values in the entorhinal cortex $(r=-0.2141$, $\mathrm{P}=0.0275$ ).

Figures 5 and 6 and Table 3 summarize the correlation analysis results of the APTw and MTR signals with age. The APTw signal intensity values showed significant positive correlations with age in 4 of 12 ROIs: the white matter in the temporal lobe $(\mathrm{r}=0.2628, \mathrm{P}=0.0065)$; the white matter in the frontal lobe $(r=0.4182, \mathrm{P}<0.0001)$; the gray matter in the frontal lobe $(\mathrm{r}=0.2065, \mathrm{P}=0.0337)$; and the caudate nucleus $(\mathrm{r}=0.2295, \mathrm{P}=0.0180)$. In addition, the APTw values indicated a statistically insignificant increasing trend with age $(r>0$, $\mathrm{P}>0.05$ ) in five ROIs (the gray matter in the temporal lobe, the white matter in the occipital lobe, the entorhinal cortex, the thalamus, and the putamen). Nevertheless, the MTR signal intensity values of the pons $(r=0.2856, P=0.0030)$, the white matter in the occipital lobe $(\mathrm{r}=0.1972, \mathrm{P}=0.0427)$, and the gray matter in the occipital lobe $(\mathrm{r}=0.1964, \mathrm{P}=0.0436)$ showed significant positive correlations with age, while the MTR values of the entorhinal cortex $(r=-0.1942, \mathrm{P}=0.0461)$ displayed significant negative correlations with age.

As shown in Table 4 and Figures $S 2, S 3$, the data of all 12 ROIs had relatively poor goodness of fit $\left(\mathrm{R}^{2}<0.2\right)$ to the second-order polynomial model. However, it can be seen that the $\mathrm{B}_{2}$ coefficients of the APTw/age data-fitting were opposite of those of the MTR/age data-fitting in 8 of 12 ROIs.

\section{Discussion}

This study demonstrated the feasibility and value of using the APTw MRI signal as a new imaging biomarker for exploring normal aging. Overall, the mean APTw values in the older group were higher than those in the younger group. The ANOVA analyses showed significant differences among the five age groups in the three white matter regions. The Pearson correlation analyses showed positive correlations with age in most brain regions analyzed (4 of 12 ROIs with significant positive correlations and 5 with increasing trends). As a comparison, the mean MTR values did not appear to be significantly different among the five age groups, but they indicated positive correlations with age in 6 of 12 ROIs (3 with significant positive correlations and 3 with increasing trends). In addition, the mean APTw and MTR values revealed significant correlations in 11 of 12 ROIs (10 with significant positive correlations and 1 with a significant negative correlation).

APT imaging quantified by $\mathrm{MTR}_{\text {asym }}(3.5 \mathrm{ppm})$ is sensitive to mobile proteins in tissues, for instance, proteins in the cytoplasm (41), and conventional MT imaging quantified by MTR can detect semi-solid macromolecules that exist in the relatively solid environment of cells, such as proteins in the cell membrane and nucleus (33). Theoretically, the APTw and MTR values are associated with the concentrations of mobile proteins and semi-solid macromolecules, respectively, in addition to some other factors (20). Misfolded protein aggregation is a typical feature of brain aging $(42,43)$. In aging brains, the most commonly altered proteins are $\beta$-amyloid, hyperphosphorylated forms of microtubule-associated tau, $\alpha$-synuclein, and transactive response DNA binding protein 43 (TDP43). Specifically, $\beta$-amyloid and tau may cause Alzheimer's disease, 

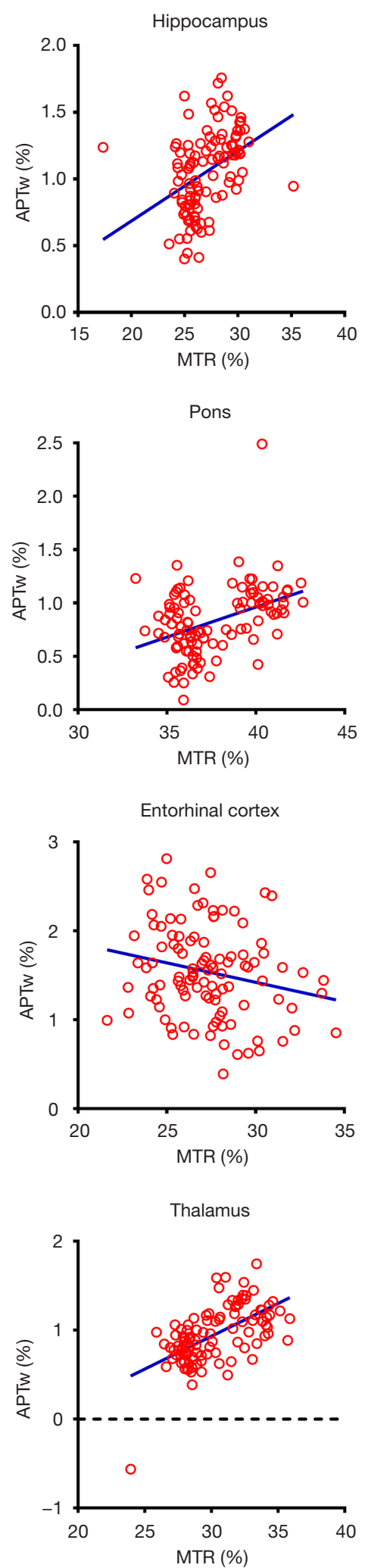

White matter in temporal lobe

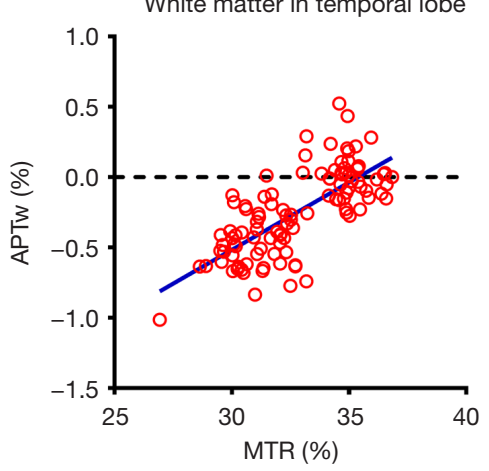

White matter in occipital lobe

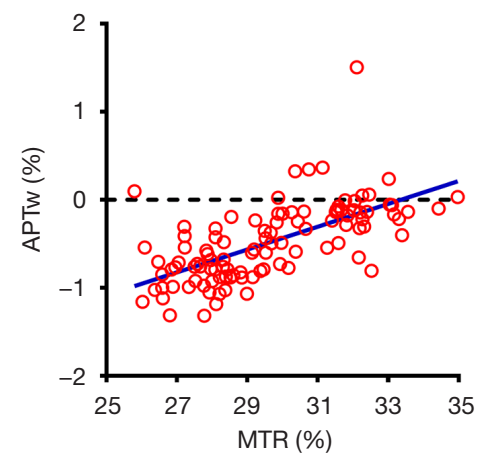

White matter in frontal lobe

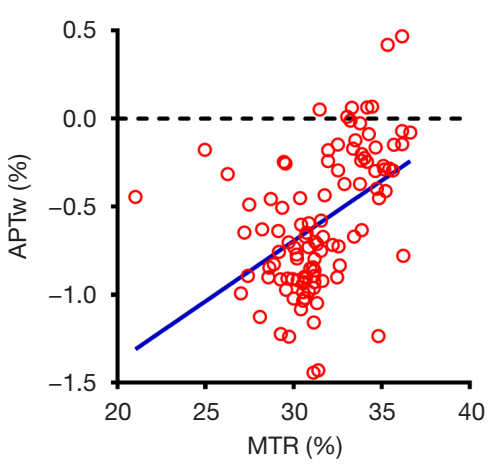

Putamen

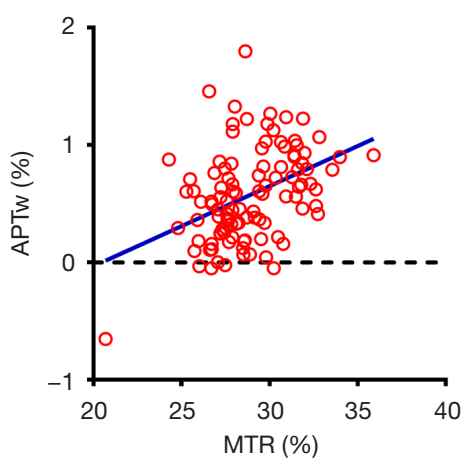

Gray matter in temporal lobe

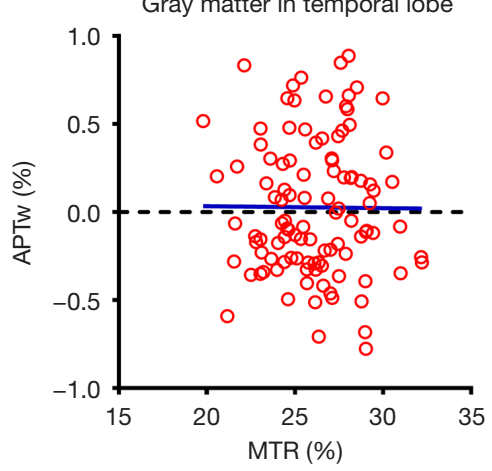

Gray matter in occipital lobe

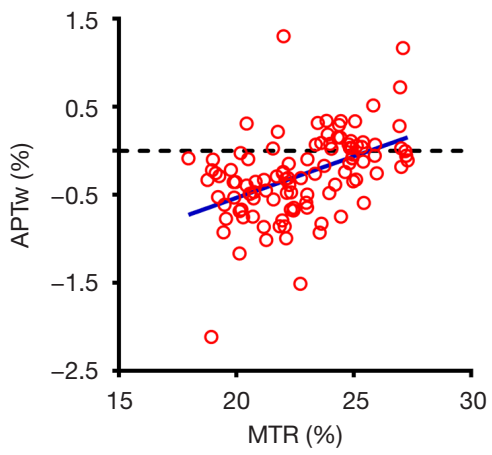

Gray matter in frontal lobe

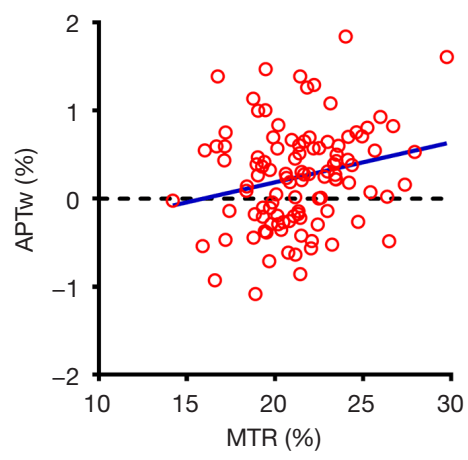

Caudate nucleus

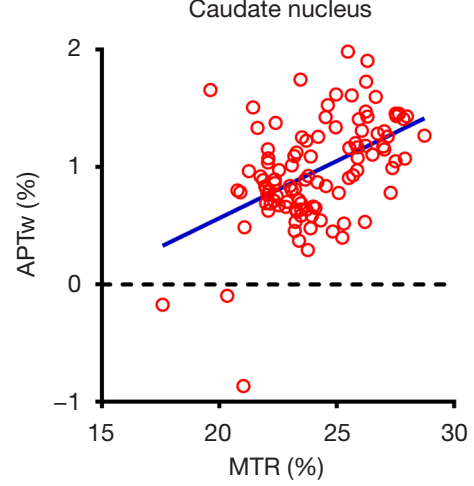

Figure 4 The Pearson correlation analysis between APTw and MTR signals in the 12 regions of interest (ROIs). MTR, magnetization transfer ratio; APTw, amide proton transfer-weighted. 
Table 2 The Pearson correlation analysis results between APTw and MTR signals in the 12 regions of interest (ROIs)

\begin{tabular}{lcc}
\hline Variable & $r$ & $\mathrm{P}$ \\
\hline Hippocampus & 0.4016 & $<0.0001^{*}$ \\
White matter in temporal lobe & 0.7269 & $<0.0001^{*}$ \\
Gray matter in temporal lobe & -0.0073 & 0.9410 \\
Pons & 0.4062 & $<0.0001^{\star}$ \\
White matter in the occipital lobe & 0.6496 & $<0.0001^{*}$ \\
Gray matter in the occipital lobe & 0.4690 & $<0.0001^{*}$ \\
Entorhinal cortex & -0.2141 & $0.0275^{\star}$ \\
White matter in frontal lobe & 0.4638 & $<0.0001^{\star}$ \\
Gray matter in the frontal lobe & 0.2214 & $0.0226^{*}$ \\
Thalamus & 0.5907 & $<0.0001^{*}$ \\
Putamen & 0.4110 & $<0.0001^{*}$ \\
Caudate nucleus & 0.4821 & $<0.0001^{*}$ \\
\hline
\end{tabular}

*, P<0.05. APTw, amide proton transfer-weighted; MTR, magnetization transfer ratio.

$\alpha$-synuclein may lead to Parkinson's disease and dementia with Lewy bodies, and TDP43 may result in amyotrophic lateral sclerosis and frontotemporal lobar degeneration with TDP (44-47). Previous postmortem studies have also demonstrated that these altered proteins can accumulate in the brains of cognitively healthy old people (48-52). Therefore, the concentration of semi-solid macromolecules and mobile proteins in brain tissues may increase relatively with age, which is consistent with the previous report (53). Notably, as the area affected earliest by pathological proteins (54), the entorhinal cortex should have an increasing MTR value in the aging brain. However, our result seemed to be the opposite. The significant negative correlation between entorhinal cortex MTR and age may be attributable to the death of entorhinal cortex neurons and degeneration (55).

Interestingly, the APTw signals in the temporal lobe, the occipital lobe, and the frontal lobe were higher in the gray matter than in the white matter (56) (Figure 2), a trend that was opposite to the MTR signals (Figure 3). The reason for this may be attributable to the fact that grey matter contains numerous cell bodies and relatively few myelinated axons, whereas white matter involves relatively few cell bodies and mainly comprises long-range myelinated axons (57). The myelinated axons have a large amount of semi-solid lipids (cholesterol, phospholipids, and glycolipids) and structural proteins, while the cell bodies of neurons are rich in mobile cytoplasmic proteins $(58,59)$. Moreover, the APTw/age data-fitting parabolas opened upward in most cerebral regions (9 of 12 ROIs), in contrast to the MTR/age datafitting parabolas. This may imply that the mobile protein content in aging brains decreased in these cerebral regions during the young stage [as observed during pediatric brain development (60)] and then increased gradually, contrary to the trend of the semi-solid macromolecular content change. The exact molecular mechanism behind this needs to be explored in a future study.

This study had several limitations. Firstly, four cerebral slices were acquired by a single-slice protocol, and so the MRI signals of other brain regions were unexplored in this study. In the future, we intend to expand the coverage of APTw MRI to the whole brain by using a three-dimensional (3D) APT imaging acquisition protocol that has been reported previously (61). Secondly, ROI placement was manually implemented due to the limited slice, which was difficult for the cortical gray matter. An automatic segmentation based on 3D APT imaging acquisition may improve the ROI accuracy in the future. Finally, the upfield nuclear Overhauser enhancement signal, from semisolid and mobile protons and some other possible effects, might have contaminated the APTw signal quantified by $\mathrm{MTR}_{\text {asym }}(3.5 \mathrm{ppm})$ in this study (20). Several modified APTw imaging acquisition or analysis methods may be applied to quantify pure APT effects in a future study (62-68). Notably, it has been demonstrated that the APT effect is dominant in APTw imaging, and the possible impact of the water $\mathrm{T}_{1}$ on APTw imaging was actually slight for the pulse sequence parameters applied here $(65,66)$.

In conclusion, this exploratory study evaluated normal brain aging by APTw imaging for the first time. Our early results have indicated that there is great potential for $\mathrm{APTw}$ MRI to provide important complementary information with which to assess normal brain aging at the protein level, in a non-invasive manner. Further research about normal brain aging with the combined APTw and MTR imaging biomarkers may assist in the early detection of aging-related neurodegenerative disorders and in monitoring the clinical therapeutic effects. 

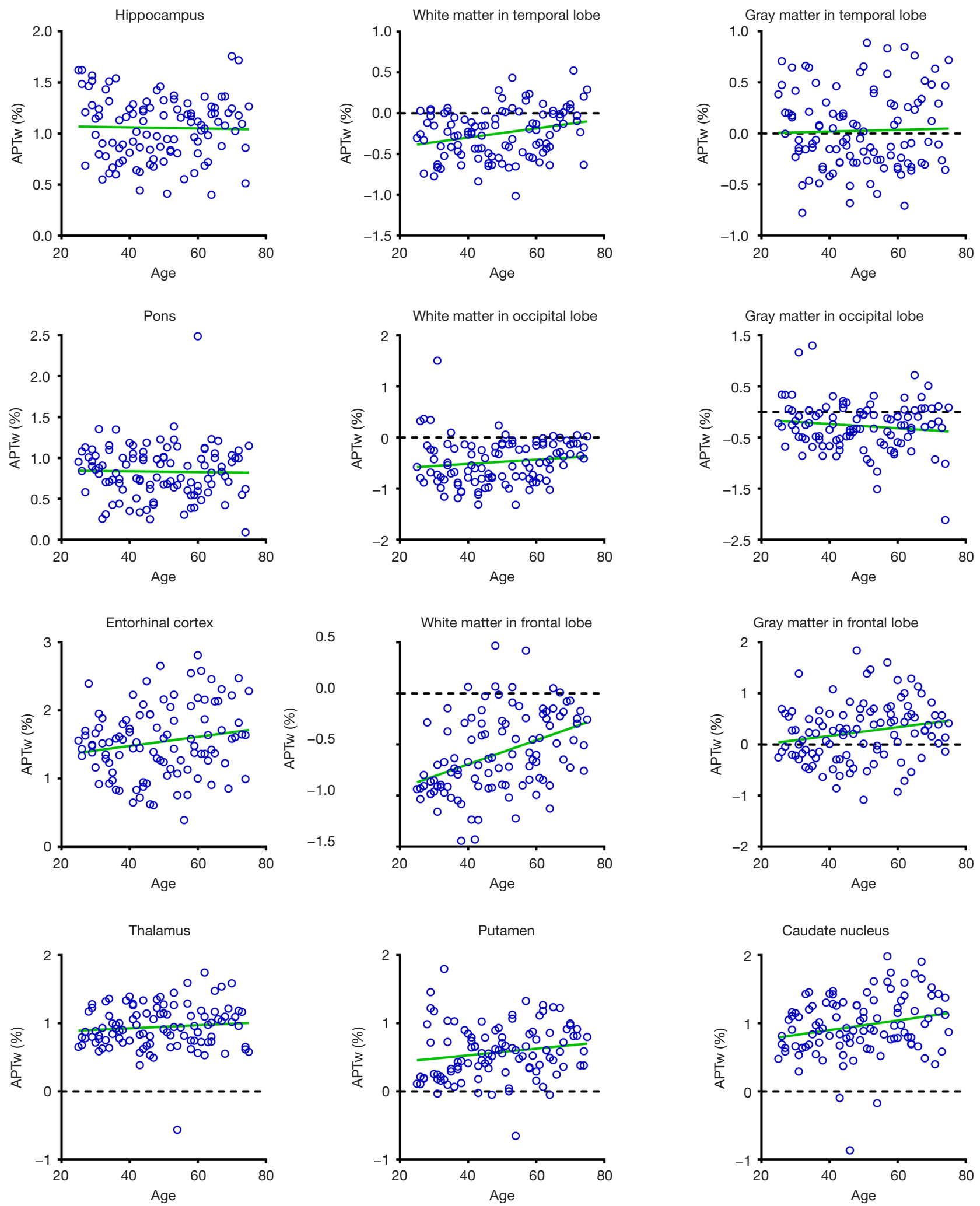

Figure 5 The Pearson correlation analysis of APTw signal with age in the 12 regions of interest (ROIs). APTw, Amide proton transferweighted. 

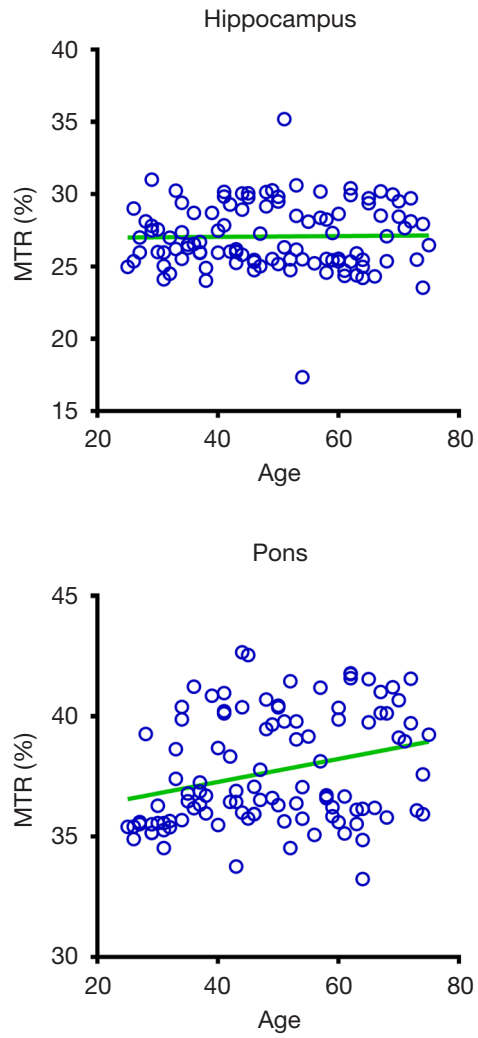

Entorhinal cortex
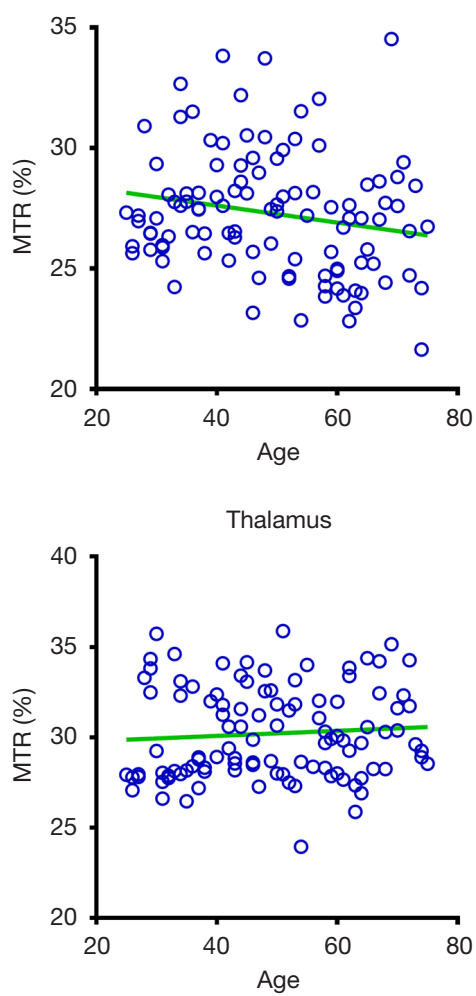

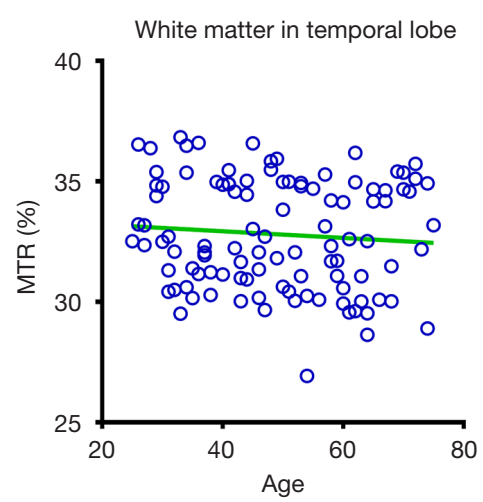

White matter in occipital lobe

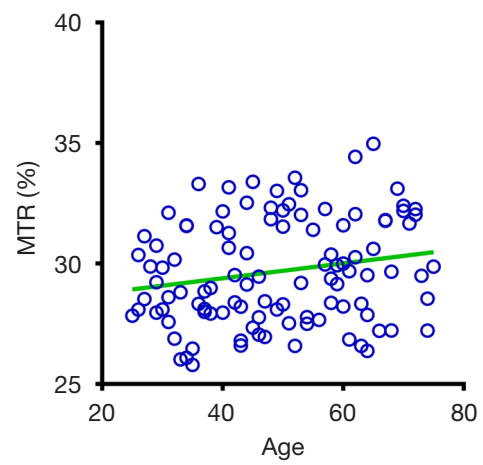

White matter in frontal lobe

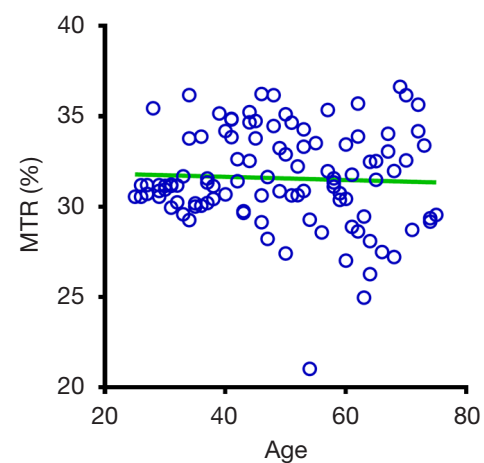

Putamen

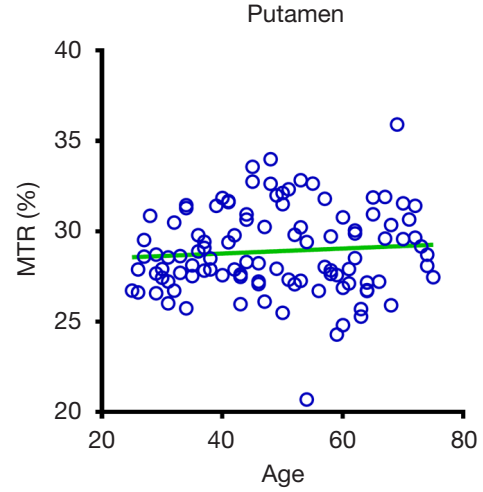

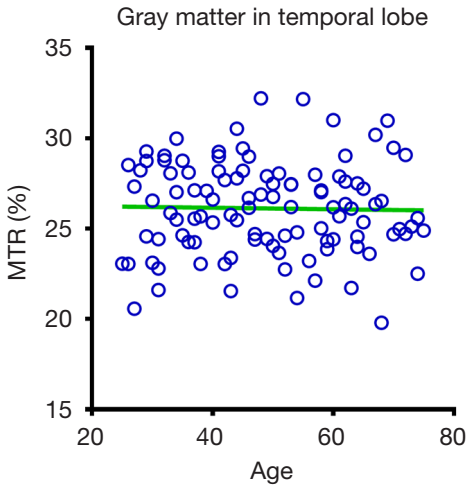

Gray matter in occipital lobe

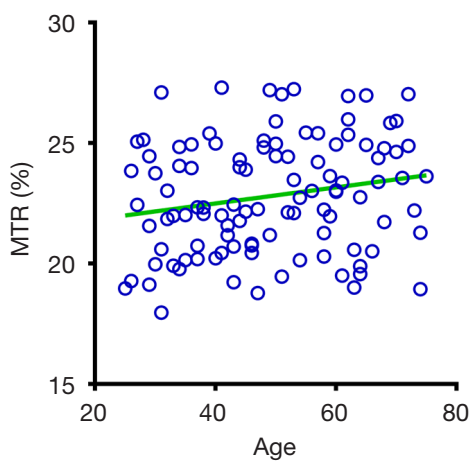

Gray matter in frontal lobe

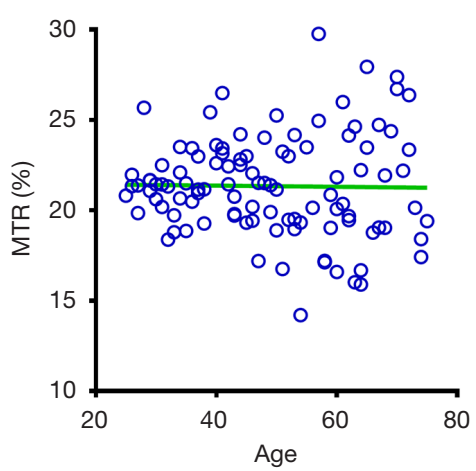

Caudate nucleus

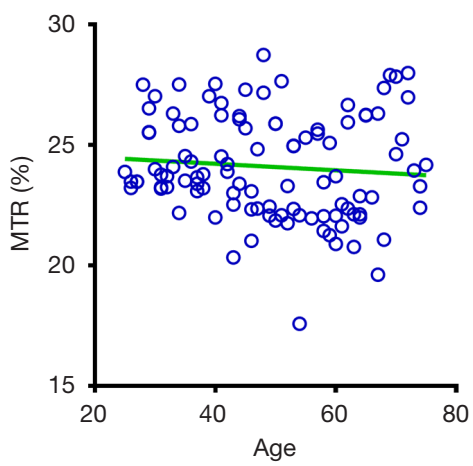

Figure 6 The Pearson correlation analysis of MTR signal with age in the 12 regions of interest (ROIs). MTR, magnetization transfer ratio. 
Table 3 The Pearson correlation analysis results of APTw and MTR signals with age in the 12 regions of interest (ROIs)

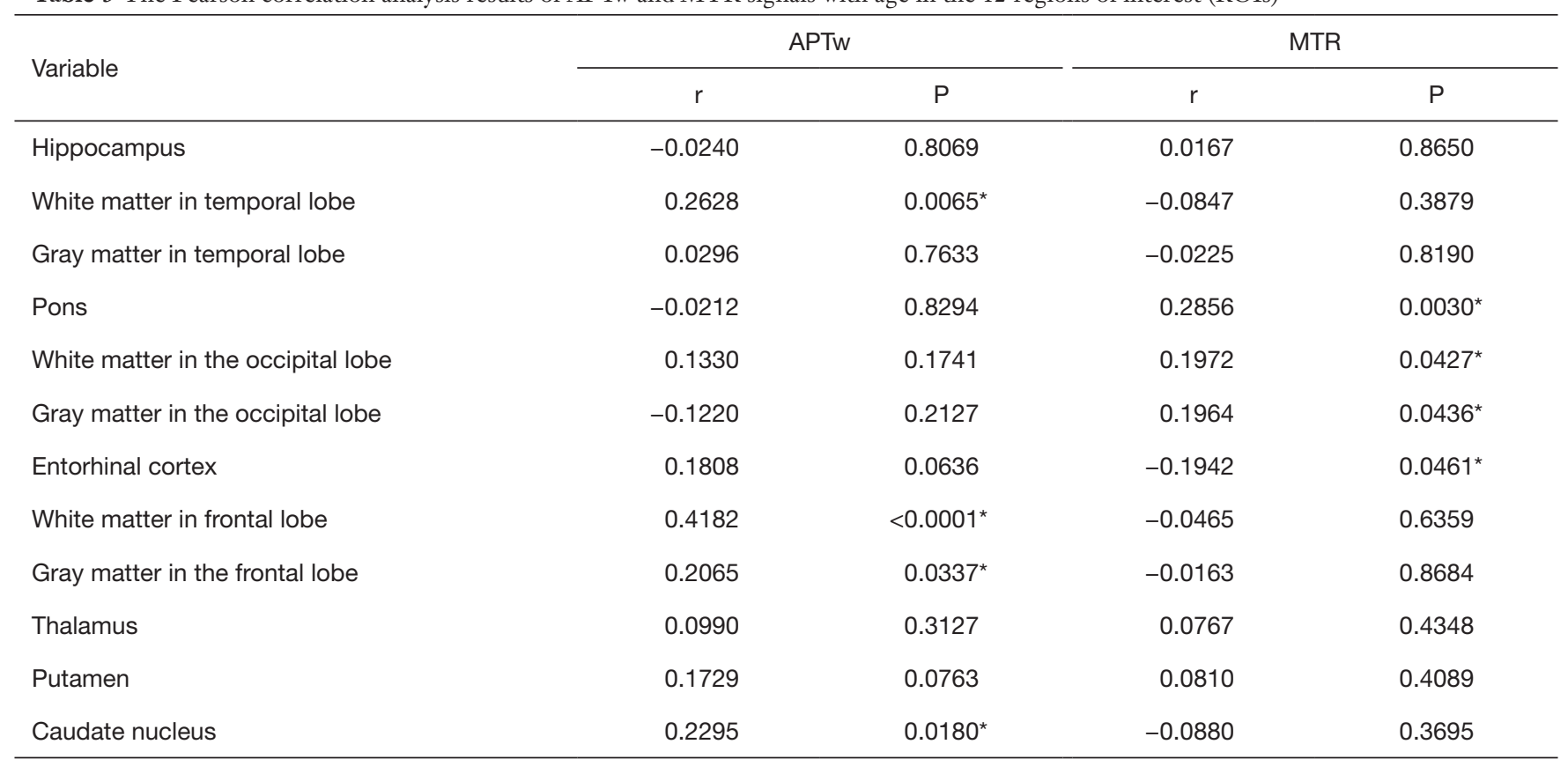

*, P<0.05. APTw, amide proton transfer-weighted; MTR, magnetization transfer ratio.

Table 4 The non-linear regression analysis of APTw and MTR values $(\mathrm{Y})$ versus age $(\mathrm{X})$ using the model $\mathrm{Y}=\mathrm{B}_{2} \mathrm{X}^{2}+\mathrm{B}_{1} \mathrm{X}+\mathrm{B}_{0}$ in the 12 regions of interest (ROIs)

\begin{tabular}{|c|c|c|c|c|c|c|c|c|}
\hline ROls & \multicolumn{4}{|c|}{ APTw } & \multicolumn{4}{|c|}{ MTR } \\
\hline Hippocampus & 2.1820 & -0.0487 & 0.0005 & 0.0837 & 26.170 & 0.0365 & -0.0003 & 0.0010 \\
\hline White matter in temporal lobe & 0.1522 & -0.0240 & 0.0003 & 0.1016 & 37.870 & -0.2060 & 0.0019 & 0.0310 \\
\hline Gray matter in temporal lobe & 1.1390 & -0.0497 & 0.0005 & 0.0578 & 22.810 & 0.1494 & -0.0015 & 0.0125 \\
\hline White matter in the occipital lobe & 0.9705 & -0.0683 & 0.0007 & 0.1095 & 27.510 & 0.0591 & -0.0003 & 0.0395 \\
\hline Gray matter in the occipital lobe & 0.5811 & -0.0326 & 0.0003 & 0.0268 & 19.640 & 0.1003 & -0.0007 & 0.0413 \\
\hline Entorhinal cortex & 1.9350 & -0.0250 & 0.0003 & 0.0452 & 24.490 & 0.1634 & -0.0020 & 0.0581 \\
\hline Putamen & 0.5302 & -0.0036 & 0.0001 & 0.0315 & 26.060 & 0.1086 & -0.0010 & 0.0119 \\
\hline Caudate nucleus & 0.6330 & 0.0063 & 0.0001 & 0.0527 & 28.960 & -0.1971 & 0.0019 & 0.0320 \\
\hline
\end{tabular}

APTw, amide proton transfer-weighted; MTR, magnetization transfer ratio. 


\section{Acknowledgments}

The authors thank Ms. Mary McAllister for editorial assistance.

Funding: None.

\section{Footnote}

Conflicts of Interest: The authors have no conflicts of interest to declare.

Ethical Statement: This study was approved by the local institutional review board. All subjects gave written informed consent before participating in this study.

Open Access Statement: This is an Open Access article distributed in accordance with the Creative Commons Attribution-NonCommercial-NoDerivs 4.0 International License (CC BY-NC-ND 4.0), which permits the noncommercial replication and distribution of the article with the strict proviso that no changes or edits are made and the original work is properly cited (including links to both the formal publication through the relevant DOI and the license). See: https://creativecommons.org/licenses/by-nc-nd/4.0/.

\section{References}

1. Trollor JN, Valenzuela MJ. Brain ageing in the new millennium. Aust N Z J Psychiatry 2001;35:788-805.

2. Cooper LL, Mitchell GF. Aortic stiffness, cerebrovascular dysfunction, and memory. Pulse (Basel) 2016;4:69-77.

3. Singer J, Trollor JN, Baune BT, Sachdev PS, Smith E. Arterial stiffness, the brain and cognition: a systematic review. Ageing Res Rev 2014;15:16-27.

4. Pase MP, Grima NA, Stough C, Scholey A, Pipingas A. Association of pulsatile and mean cerebral blood flow velocity with age and neuropsychological performance. Physiol Behav 2014;130:23-27.

5. Marsland AL, Gianaros PJ, Kuan DCH, Sheu LK, Krajina K, Manuck SB. Brain morphology links systemic inflammation to cognitive function in midlife adults. Brain Behav Immun 2015;48:195-204.

6. Yin F, Sancheti H, Patil I, Cadenas E. Energy metabolism and inflammation in brain aging and Alzheimer's disease. Free Radic Biol Med 2016;100:108-122.

7. Warren KN, Beason-Held LL, Carlson O, Egan JM, An Y, Doshi J, Davatzikos C, Ferrucci L, Resnick SM. Elevated markers of inflammation are associated with longitudinal changes in brain function in older adults. J Gerontol A Biol Sci Med Sci 2018;73:770-8.

8. García-Mesa Y, Colie S, Corpas R, Cristòfol R, Comellas F, Nebreda AR, Giménez-Llort L, Sanfeliu C. Oxidative stress is a central target for physical exercise neuroprotection against pathological brain aging. J Gerontol A Biol Sci Med Sci 2016;71:40-9.

9. Macpherson H, Roberstson B, Sünram-Lea S, Stough C, Kennedy D, Scholey A. Glucose administration and cognitive function: Differential effects of age and effort during a dual task paradigm in younger and older adults. Psychopharmacology (Berl) 2015;232:1135-42.

10. Cleeland C, Pipingas A, Scholey A, White D.

Neurochemical changes in the aging brain: A systematic review. Neurosci Biobehav Rev 2019;98:306-19.

11. Humayun H, Yao J. Imaging the aged brain: pertinence and methods. Quant Imaging Med Surg 2019;9:842-57.

12. Vinke EJ, De Groot $M$, Venkatraghavan V, Klein S, Niessen WJ, Ikram MA, Vernooij MW. Trajectories of imaging markers in brain aging: the Rotterdam Study. Neurobiol Aging 2018;71:32-40.

13. Eavani H, Habes M, Satterthwaite TD, An Y, Hsieh MK, Honnorat N, Erus G, Doshi J, Ferrucci L, BeasonHeld LL, Resnick SM, Davatzikos C. Heterogeneity of structural and functional imaging patterns of advanced brain aging revealed via machine learning methods. Neurobiol Aging 2018;71:41-50.

14. Mosconi L. Glucose metabolism in normal aging and Alzheimer's disease: methodological and physiological considerations for PET studies. Clin Transl Imaging 2013;1:217-33.

15. Schöll M, Lockhart SN, Schonhaut DR, O'Neil JP, Janabi M, Ossenkoppele R, Baker SL, Vogel JW, Faria J, Schwimmer HD, Rabinovici GD, Jagust WJ. PET imaging of tau deposition in the aging human brain. Neuron 2016;89:971-82.

16. Maass A, Landau S, Baker SL, Horng A, Lockhart SN, La Joie R, Rabinovici GD, Jagust WJ; Alzheimer's Disease Neuroimaging Initiative. Comparison of multiple tau-PET measures as biomarkers in aging and Alzheimer's disease. Neuroimage 2017;157:448-63.

17. Rentz DM, Locascio JJ, Becker JA, Moran EK, Eng E, Buckner RL, Sperling RA, Johnson KA. Cognition, reserve, and amyloid deposition in normal aging. Ann Neurol 2010;67:353-64.

18. Zhou J, Van Zijl PC. Chemical exchange saturation transfer imaging and spectroscopy. Prog Nucl Magn Reson 
Spectrosc 2006;48:109-36.

19. Dou W, Lin CY, Ding H, Shen Y, Dou C, Qian L, Wen $\mathrm{B}, \mathrm{Wu}$ B. Chemical exchange saturation transfer magnetic resonance imaging and its main and potential applications in pre-clinical and clinical studies. Quant Imaging Med Surg 2019;9:1747-66.

20. Zhou J, Heo HY, Knutsson L, van Zijl PC, Jiang S. APTweighted MRI: Techniques, current neuro applications, and challenging issues. J Magn Reson Imaging 2019;50:347-64.

21. Zhou J, Payen JF, Wilson DA, Traystman RJ, Van Zijl PC. Using the amide proton signals of intracellular proteins and peptides to detect $\mathrm{pH}$ effects in MRI. Nat Med 2003;9:1085.

22. Yuan J, Chen S, King AD, Zhou J, Bhatia KS, Zhang Q, Yeung DK, Wei J, Mok GS, Wang YX. Amide proton transfer-weighted imaging of the head and neck at $3 \mathrm{~T}$ : a feasibility study on healthy human subjects and patients with head and neck cancer. NMR Biomed 2014;27:1239-47.

23. Jiang S, Zou T, Eberhart CG, Villalobos MA, Heo HY, Zhang Y, Wang Y, Wang X, Yu H, Du Y, Zhou J. Predicting IDH mutation status in grade II gliomas using amide proton transfer-weighted (APTw) MRI. Magn Reson Med 2017;78:1100-9.

24. Jiang S, Eberhart CG, Lim M, Heo HY, Zhang Y, Blair L, Wen Z, Holdhoff M, Lin D, Huang P. Identifying recurrent malignant glioma after treatment using amide proton transfer-weighted MR imaging: a validation study with image-guided stereotactic biopsy. Clin Cancer Res 2019;25:552-61.

25. Lin Y, Luo XJ, Yu L, Zhang Y, Zhou JY, Jiang YW, Zhang C, Zhang JT, Li CM, Chen M. Amide proton transfer-weighted MRI for predicting histological grade of hepatocellular carcinoma: comparison with diffusion-weighted imaging. Quant Imaging Med Surg 2019;9:1641-51.

26. Sun PZ, Zhou J, Sun W, Huang J, van Zijl PC. Detection of the ischemic penumbra using $\mathrm{pH}$-weighted MRI. J Cereb Blood Flow Metab 2007;27:1129-36.

27. Harston GW, Tee YK, Blockley N, Okell TW, Thandeswaran S, Shaya G, Sheerin F, Cellerini M, Payne $\mathrm{S}$, Jezzard P. Identifying the ischaemic penumbra using $\mathrm{pH}$-weighted magnetic resonance imaging. Brain 2015;138:36-42.

28. Heo HY, Zhang Y, Burton TM, Jiang S, Zhao Y, van Zijl PC, Leigh R, Zhou J. Improving the detection sensitivity of $\mathrm{pH}$-weighted amide proton transfer MRI in acute stroke patients using extrapolated semisolid magnetization transfer reference signals. Magn Reson Med 2017;78:871-80.

29. Li C, Peng S, Wang R, Chen H, Su W, Zhao X, Zhou J, Chen M. Chemical exchange saturation transfer MR imaging of Parkinson's disease at 3 Tesla. Eur Radiol 2014;24:2631-9.

30. Zhang H, Wang W, Jiang S, Zhang Y, Heo HY, Wang X, Peng Y, Wang J, Zhou J. Amide proton transfer-weighted MRI detection of traumatic brain injury in rats. J Cereb Blood Flow Metab 2017;37:3422-32.

31. Mao Y, Zhuang Z, Chen Y, Zhang X, Shen Y, Lin G, Wu R. Imaging of glutamate in acute traumatic brain injury using chemical exchange saturation transfer. Quant Imaging Med Surg 2019;9:1652-63.

32. Zhang Z, Zhang C, Yao J, Chen X, Gao F, Jiang S, Chen W, Zhou J, Wang G. Protein-based amide proton transfer-weighted MR imaging of amnestic mild cognitive impairment. Neuroimage Clin 2020;25:102153.

33. Henkelman RM, Stanisz GJ, Graham SJ. Magnetization transfer in MRI: a review. NMR Biomed 2001;14:57-64.

34. Wen Z, Hu S, Huang F, Wang X, Guo L, Quan X, Wang $\mathrm{S}$, Zhou J. MR imaging of high-grade brain tumors using endogenous protein and peptide-based contrast. Neuroimage 2010;51:616-22.

35. Zhang Y, Heo HY, Lee DH, Zhao X, Jiang S, Zhang K, Li $\mathrm{H}$, Zhou J. Selecting the reference image for registration of CEST series. J Magn Reson Imaging 2016;43:756-61.

36. Zhao X, Wen Z, Huang F, Lu S, Wang X, Hu S, Zu D, Zhou J. Saturation power dependence of amide proton transfer image contrasts in human brain tumors and strokes at 3 T. Magn Reson Med 2011;66:1033-41.

37. Botwinick J. Aging and behavior: A comprehensive integration of research findings. Springer; 2013.

38. Sia DI, Martin S, Wittert G, Casson RJ. Age-related change in contrast sensitivity among Australian male adults: Florey Adult Male Ageing Study. Acta Ophthalmol 2013;91:312-7.

39. Hoertel N, McMahon K, Olfson M, Wall MM, Rodríguez-Fernández JM, Lemogne C, Limosin F, Blanco C. A dimensional liability model of age differences in mental disorder prevalence: evidence from a national sample. J Psychiatr Res 2015;64:107-13.

40. Benjamini Y, Hochberg Y. Controlling the false discovery rate: a practical and powerful approach to multiple testing. J R Stat Soc Series B Stat Methodol 1995;57:289-300.

41. Yan K, Fu Z, Yang C, Zhang K, Jiang S, Lee DH, Heo HY, Zhang Y, Cole RN, Van Eyk JE. Assessing amide proton transfer (APT) MRI contrast origins in $9 \mathrm{~L}$ gliosarcoma in 
the rat brain using proteomic analysis. Mol Imaging Biol 2015;17:479-87.

42. Taylor JP, Hardy J, Fischbeck KH. Toxic proteins in neurodegenerative disease. Science 2002;296:1991-95.

43. Agorogiannis EI, Agorogiannis GI, Papadimitriou A, Hadjigeorgiou GM. Protein misfolding in neurodegenerative diseases. Neuropathology and Applied Neurobiology 2004;30:215-24.

44. Thal DR, Rüb U, Orantes M, Braak H. Phases of A deposition in the human brain and its relevance for the development of AD. Neurology 2002;58:1791-800.

45. McKeith IG, Dickson DW, Lowe J, Emre M, O'Brien JT, Feldman H, Cummings J, Duda JE, Lippa C, Perry EK, Aarsland D, Arai H, Ballard CG, Boeve B, Burn DJ, Costa D, Del Ser T, Dubois B, Galasko D, Gauthier S, Goetz CG, Gomez-Tortosa E, Halliday G, Hansen LA, Hardy J, Iwatsubo T, Kalaria RN, Kaufer D, Kenny RA, Korczyn A, Kosaka K, Lee VM, Lees A, Litvan I, Londos E, Lopez OL, Minoshima S, Mizuno Y, Molina JA, MukaetovaLadinska EB, Pasquier F, Perry RH, Schulz JB, Trojanowski JQ, Yamada M; Consortium on DLB. Diagnosis and management of dementia with Lewy bodies: third report of the DLB Consortium. Neurology 2005;65:1863-72.

46. Neumann M, Sampathu DM, Kwong LK, Truax AC, Micsenyi MC, Chou TT, Bruce J, Schuck T, Grossman M, Clark CM. Ubiquitinated TDP-43 in frontotemporal lobar degeneration and amyotrophic lateral sclerosis. Science 2006;314:130-3.

47. Braak H, Del Tredici K. The pathological process underlying Alzheimer's disease in individuals under thirty. Acta Neuropathologica 2011;121:171-81.

48. Bennett DA, Wilson RS, Boyle PA, Buchman AS, Schneider JA. Relation of neuropathology to cognition in persons without cognitive impairment. Ann Neurol 2012;72:599-609.

49. Arnold SJ, Dugger BN, Beach TG. TDP-43 deposition in prospectively followed, cognitively normal elderly individuals: correlation with argyrophilic grains but not other concomitant pathologies. Acta Neuropathologica 2013;126:51-7.

50. Kovacs GG, Milenkovic I, Wöhrer A, Höftberger R, Gelpi E, Haberler C, Hönigschnabl S, Reiner-Concin A, Heinzl H, Jungwirth S. Non-Alzheimer neurodegenerative pathologies and their combinations are more frequent than commonly believed in the elderly brain: a community-based autopsy series. Acta Neuropathologica 2013;126:365-84.

51. Dugger BN, Hentz JG, Adler CH, Sabbagh MN,
Shill HA, Jacobson S, Caviness JN, Belden C, DriverDunckley E, Davis KJ. Clinicopathological outcomes of prospectively followed normal elderly brain bank volunteers. J Neuropath Exp Neurol 2014;73:244-52.

52. Uchino A, Takao M, Hatsuta H, Sumikura H, Nakano Y, Nogami A, Saito Y, Arai T, Nishiyama K, Murayama S. Incidence and extent of TDP-43 accumulation in aging human brain. Acta Neuropathol Commun 2015;3:35.

53. Elobeid A, Libard S, Leino M, Popova SN, Alafuzoff I. Altered proteins in the aging brain. J Neuropathol Exp Neurol 2016;75:316-25.

54. Petrella JR. Neuroimaging and the search for a cure for Alzheimer disease. Radiology 2013;269:671-91.

55. Tambasco N, Nigro P, Romoli M, Simoni S, Parnetti L, Calabresi P. Magnetization transfer MRI in dementia disorders, Huntington's disease and parkinsonism. J Neurol Sci 2015;353:1-8.

56. Xu X, Yadav NN, Zeng H, Jones CK, Zhou J, van Zijl PC, $\mathrm{Xu} \mathrm{J}$. Magnetization transfer contrast-suppressed imaging of amide proton transfer and relayed nuclear overhauser enhancement chemical exchange saturation transfer effects in the human brain at 7T. Magn Reson Med 2016;75:88-96.

57. Bear MF, Connors BW, Paradiso MA. Neuroscience. Lippincott Williams \& Wilkins; 2007.

58. Laule C, Vavasour IM, Kolind SH, Li DK, Traboulsee TL, Moore GW, MacKay AL. Magnetic resonance imaging of myelin. Neurotherapeutics 2007;4:460-84.

59. Barkovich AJ. Concepts of myelin and myelination in neuroradiology. AJNR Am J Neuroradiol 2000;21:1099-109.

60. Zhang H, Kang H, Zhao X, Jiang S, Zhang Y, Zhou J, Peng Y. Amide proton transfer (APT) MR imaging and magnetization transfer (MT) MR imaging of pediatric brain development. Eur Radiol 2016;26:3368-76.

61. Zhou J, Zhu H, Lim M, Blair L, Quinones-Hinojosa A, Messina SA, Eberhart CG, Pomper MG, Laterra J, Barker PB. Three-dimensional amide proton transfer MR imaging of gliomas: initial experience and comparison with gadolinium enhancement. J Magn Reson Imaging 2013;38:1119-28.

62. Jin T, Wang P, Zong X, Kim SG. MR imaging of the amide-proton transfer effect and the $\mathrm{pH}$-insensitive nuclear overhauser effect at 9.4 T. Magn Reson Med 2013;69:760-70.

63. Zu Z, Janve VA, Xu J, Does MD, Gore JC, Gochberg DF. A new method for detecting exchanging amide protons using chemical exchange rotation transfer. Magn Reson Med 2013;69:637-47.

64. Cai K, Singh A, Poptani H, Li W, Yang S, Lu Y, 
Hariharan H, Zhou XJ, Reddy R. CEST signal at 2ppm (CEST@2ppm) from Z-spectral fitting correlates with creatine distribution in brain tumor. NMR Biomed 2015;28:1-8.

65. Heo HY, Zhang Y, Lee DH, Hong X, Zhou J.

Quantitative assessment of amide proton transfer (APT) and nuclear Overhauser enhancement (NOE) imaging with extrapolated semi-solid magnetization transfer reference (EMR) signals: application to a rat glioma model at 4.7 Tesla. Magn Reson Med 2016;75:137-49.

66. Heo HY, Zhang Y, Jiang S, Lee DH, Zhou J. Quantitative assessment of amide proton transfer (APT) and nuclear overhauser enhancement (NOE) imaging with

Cite this article as: Zhang Z, Zhang C, Yao J, Gao F, Gong T, Jiang S, Chen W, Zhou J, Wang G. Amide proton transferweighted magnetic resonance imaging of human brain aging at 3 Tesla. Quant Imaging Med Surg 2020;10(3):727-742. doi: 10.21037/qims.2020.02.22 extrapolated semisolid magnetization transfer reference (EMR) signals: II. Comparison of three EMR models and application to human brain glioma at 3 Tesla. Magn Reson Med 2016;75:1630-9.

67. Heo HY, Han Z, Jiang S, Schar M, van Zijl PCM, Zhou J. Quantifying amide proton exchange rate and concentration in chemical exchange saturation transfer imaging of the human brain. Neuroimage 2019;189:202-13.

68. Shaghaghi M, Chen WW, Scotti A, Ye HQ, Zhang Y, Zhu WZ, Cai KJ. In vivo quantification of proton exchange rate in healthy human brains with omega plot. Quant Imaging Med Surg 2019;9:1686-96. 

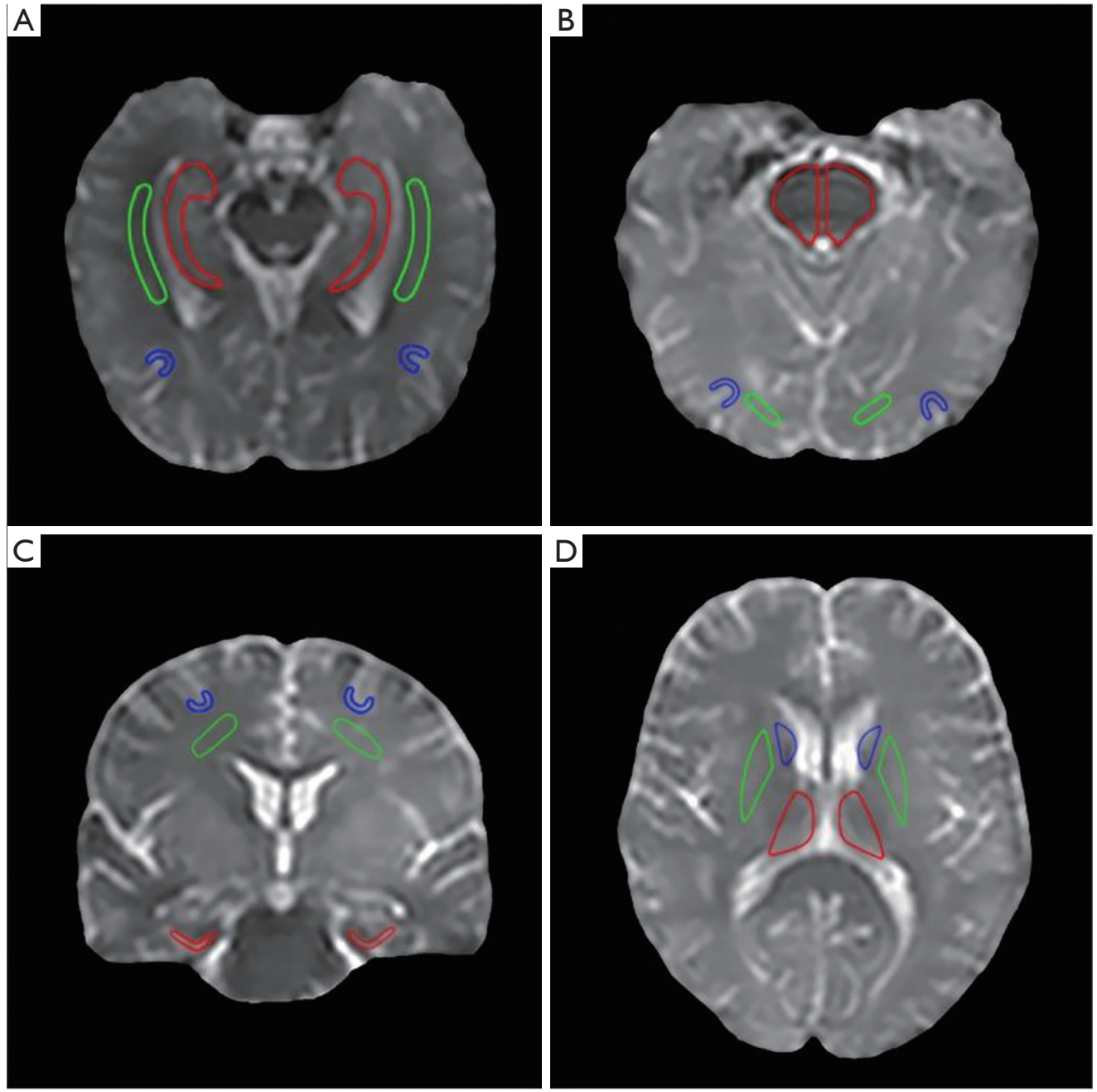

Figure S1 An example of the 12 regions of interest (ROIs) for quantitative analyses: (A) the first slice: hippocampus (red); white matter in the temporal lobe (green); and gray matter in the temporal lobe (blue); (B) the second slice: pons (red); white matter in the occipital lobe (green); and gray matter in the occipital lobe (blue); (C) the third slice: entorhinal cortex (red); white matter in the frontal lobe (green); and gray matter in the frontal lobe (blue); and (D) the fourth slice: thalamus (red); putamen (green); and caudate nucleus (blue). 

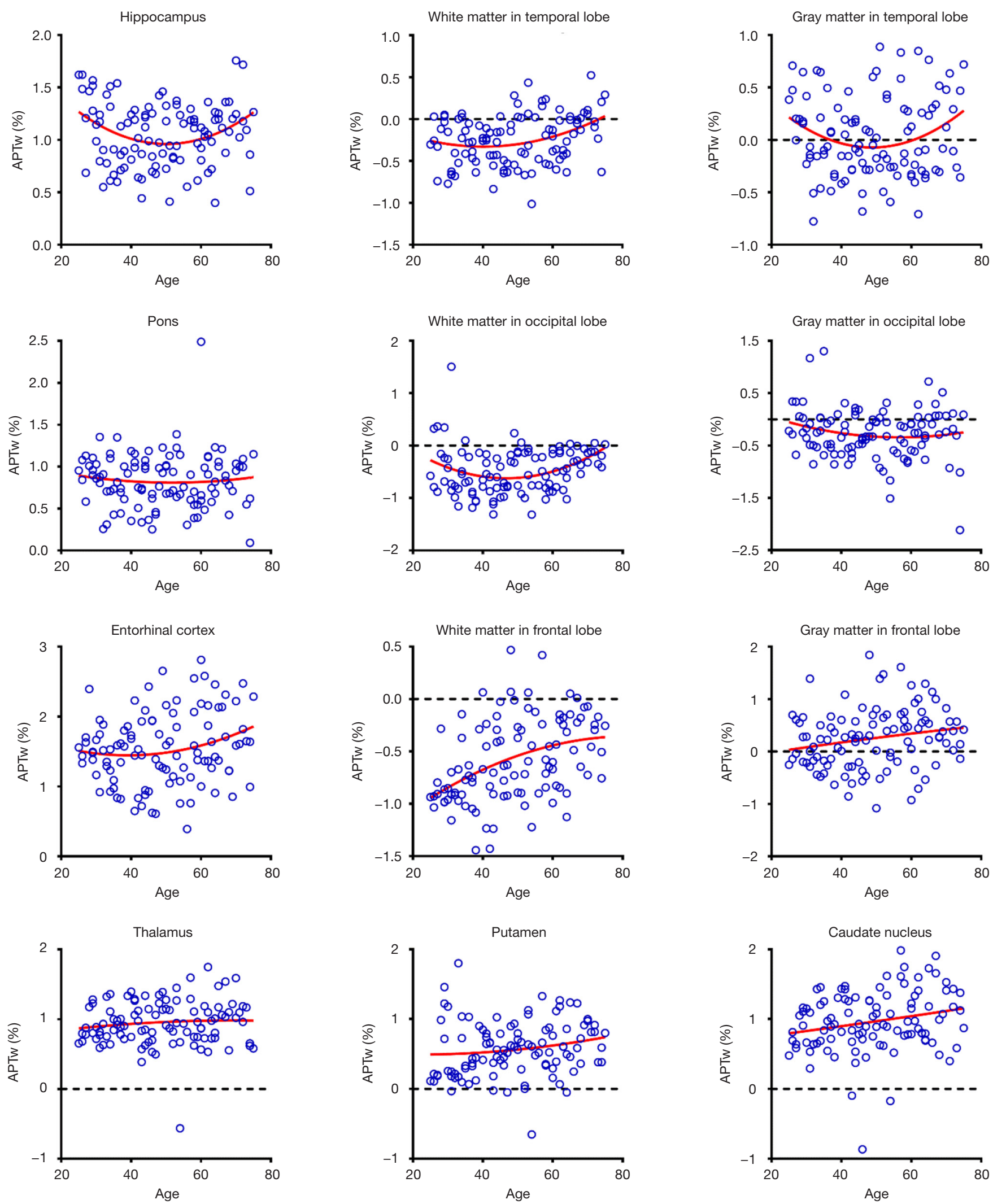

Figure S2 The non-linear regression analysis of APTw value versus age in the 12 regions of interest (ROIs). APTw, Amide proton transferweighted. 

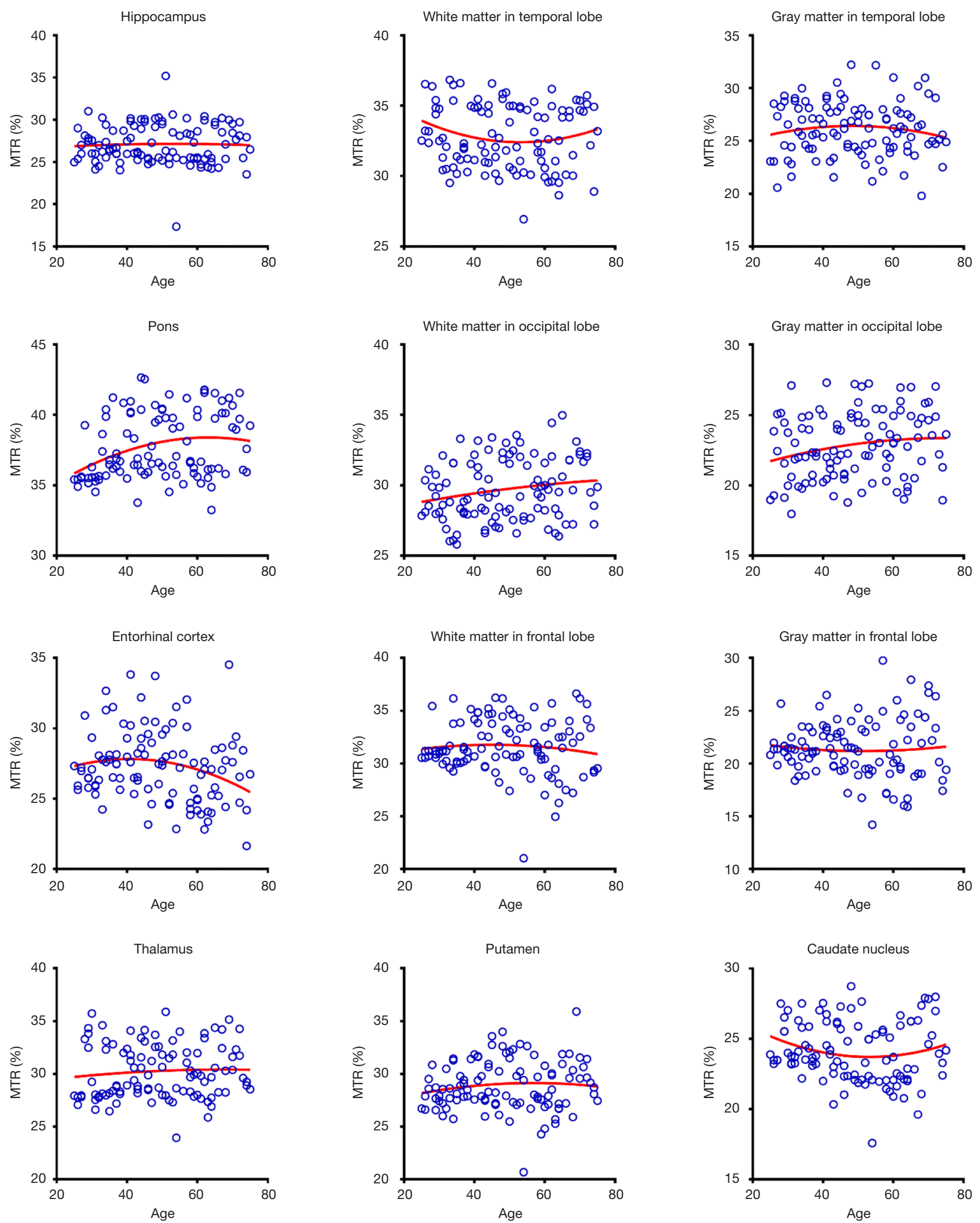

Figure S3 The non-linear regression analysis of MTR value versus age in the 12 regions of interest (ROIs). MTR, magnetization transfer ratio. 